\title{
Theoretical Framework to Assess Peripheral Intravenous Catheter Insertion and Care Practices in Paediatric Patients: A Literature Review
}

\author{
$* 1^{\text {st }}$ Ferika Indarwati \\ School of Nursing, Faculty of Medicine \\ and Health Science \\ Universitas Muhammadiyah \\ Yogyakarta \\ Yogyakarta, Indonesia \\ School of Nursing, Institute of Health \\ and Biomedical Innovation \\ Queensland University of Technology \\ Queensland, Australia \\ ferika.indarwati@umy.ac.id
}

\author{
$2^{\text {nd }}$ Judy Munday \\ School of Nursing, Centre of \\ Healthcare Transformation \\ Queensland University of Technology \\ Queensland, Australia \\ Faculty of Health and Sports Sciences \\ University of Agder \\ Grimstad, Norway \\ judy.munday@qut.edu.au
}

\author{
$3^{\text {rd }}$ Samantha Keogh \\ Centre of Healthcare Transformation \\ Queensland University of Technology \\ Queensland, Australia \\ s2.keogh@qut.edu.au
}

\begin{abstract}
Theoretical frameworks are used to guide research processes as well as to accommodate the multiple constructs of the phenomena being evaluated. A literature review was undertaken to identify a theoretical framework to inform a study of paediatric peripheral intravenous catheter (PIVC) utilization in hospitals in Indonesia. The literature search was undertaken in four databases: US National Library of Medicine National Institutes of Health, Cumulative Index of Nursing and Allied Health (CINAHL), Embase, and Google Scholar using the predefined keywords. Further searches across reference lists were also conducted. All relevant articles were screened and analyzed for inclusion and exclusion criteria based on the research questions, aim and objectives. Among theoretical frameworks identified in the literature the Donabedian theoretical framework offered the most comprehensive model to assess the current state of paediatric peripheral intravenous catheter insertion and care practices in hospitals. The Donabedian framework provided a construct to investigate the interdependent components of structure, process, and outcomes (S-P-O) of PIVC insertion and management service in paediatric population. This framework also supported the use of multiple data collection methods to study the PIVC service. The Donabedian S-P-O model provides a useful framework to assess healthcare service in general and in paediatric PIVC in particular. The use of this framework enables the researcher to identify relevant indicators as well as to understand the strengths and weaknesses of each dimension of the healthcare services.
\end{abstract}

Keywords- healthcare service evaluation, theoretical framework, the Donabedian model, paediatric, peripheral intravenous catheter, nursing care

\section{INTRODUCTION}

The majority of paediatric patients in hospitals have at least one peripheral intravenous catheter (PIVC) inserted during their hospital stay making PIVC insertion and care the most frequent invasive procedure undertaken by healthcare staff (1).It is primarily used for drug and fluids administration, and only a small percentage are inserted for other purposes such as blood transfusion and nutrition deliveries(2).PIVC characteristics, patient characteristics, documentation, failure and complications, and risk factors for failure are among variables mostly reported in these studies(3, 4). Despite the vast amount of literature regarding PIVC use and practice published worldwide, studies investigating PIVC use and practices including patients' experience, in the paediatric population in Indonesia remain scarce.

The assessment of PIVC insertion and management practices in paediatric patients is crucial to ensure patient safety, to reduce costs and to improve patient satisfaction [5]. Assessment and evaluation of the healthcare service performance are integral and fundamental parts of planning, organisation and administration [5-7].Evaluation of PIVC insertion and care practices, including utilisation, staff capacity, and outcomes as well as patient experience provides a mechanism to assess the quality of the service, identify what works and what does not work, guide future improvement projects, guide health policy and planning of the management and provision of services[8]. Furthermore, assessing PIVC insertion and management practices ensures transparency, accountability and adequacy of the service for patients.

Nevertheless, assessing healthcare practices such as PIVC insertion and management practice is a complex and challenging process. Assessment of the healthcare performance is viewed as an abstract and nebulous concept to be precisely defined or objectively measured [9]. The measurement has to actually measure what it is supposed to measure, needs to be used and interpreted correctly, and should be repeatable after implementation of practice change to determine effects [5].Therefore, a guiding framework reflective of the key variables are important. A theoretical framework is a set of abstract concepts that provide a coherent explanation of certain phenomena that help the researcher to plan their study [10]. The theoretical framework connects the researcher to existing knowledge, 
gives a basis for the study hypothesis, and guides the selection of methodology and methods in the research. Therefore, in this report, the process used to identify an appropriate theoretical framework to assess PIVC use and practice in paediatric patients in Indonesia is discussed.

\section{RESULT}

The initial literature search yielded 4493 articles. After removing duplicates and screening the title, abstract and full text against the study's assertion criteria, five prominent theoretical frameworks for assessing the current state of PIVC insertion and care in paediatric patients were identified. Potential frameworks are described in Table 1.

\section{TABLE I. LIST OF THE POTENTIAL FRAMEWORKS}

\begin{tabular}{ll}
\hline \multicolumn{1}{c}{ Author, Year } & \multicolumn{1}{c}{ Health assessment main concepts } \\
\hline Ovretveit, 1992 & Professional, client and management \\
\hline Deming, 1986 & Economic indicators \\
Larrabee, 1996 & Value, beneficence, prudence and justice \\
Pasuraman, Zeithaml \& & Service quality (SERVQUAL) \\
Berry, 1985 & \\
Donabedian, 1988 & Structure-process-outcome \\
\hline
\end{tabular}

Ovretveit's framework (1992) proposed that the performance of healthcare services can be measured from three dimensions: namely professional, client, and management. The professional dimension focuses on meeting patients' needs using correct techniques and procedures. The client dimension refers to direct benefits from service to patients. The management dimension refers to efficiency in delivering the service[11]. This model is developed based on Deming's (1986) total quality management model that is mostly criticised for its lack of consistency of the concept and limited prescriptive example for each dimension, particularly if implemented in healthcare services $[12,13]$.

Larrabee (1996) developed the healthcare assessment model and conceptualised four dimensions (value, beneficence, prudence, justice) as components of healthcare service/practice quality. This model provides insights both from ethical and economic perspectives of healthcare performance[14]. Nevertheless, the four dimensions of this framework could not provide comprehensive understanding of the current studygoals, which is to gain high level understanding of PIVC use, outcomes, and process of delivery.

Parasuraman and colleagues' quality model (1985), which perceived service quality from ten dimensions namely performance consistency, communication, competence, courtesy, credibility, security, understanding, and tangibles [15]. This framework is rooted in marketing discipline and more focus on consumer satisfaction rather than other dimensions such as quality of care structures or resources, which may influence outcomes [16].

Donabedian (1966) proposed the triad structures (S), processes $(\mathrm{P})$, and outcomes $(\mathrm{O})$, known as the S-P-O, as a framework for assessing the quality of care (Figure 1).

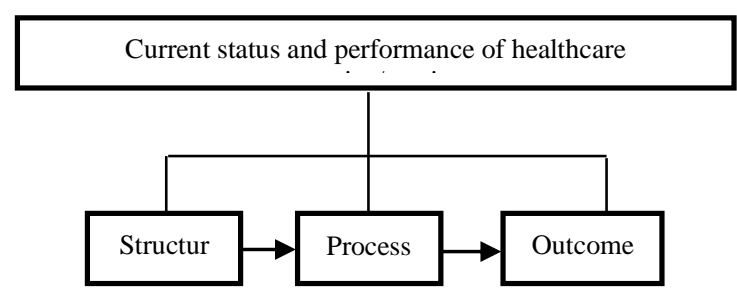

Fig. 1. The Donabedian SPO Framework (Donabedian, 2003)

The structure refers to the material, organisational and human resources characteristics used in the provision of care to clients (e.g., number and qualification or quality of staff and equipment). The process covers all activities related to care delivery including prevention, diagnosis, treatment, and rehabilitation (e.g., health professionals and patient activities related to care). Outcome focuses on the result of the care provided (e.g., disease, disability, recovery), which later also includes the patient's satisfaction and experience as an integral part of healthcare quality [9]. The three domains of structure, process, and outcome, when integrated and sourced from reliable data allow researchers or stakeholders to obtain a more comprehensive picture of care delivery. These three elements are interdependent, with each directly influenced by the antecedent [17]. The improvements in the structure of care should lead to improvements in clinical processes, which should, in turn, improve patient outcomes [18].

Donabedian's framework offers a comprehensive model to assess healthcare performance, has gained more acceptance than other conceptual models and is mostly used by health professionals [18-20] including those in vascular access research [21-25]. Further assessment of the suitability of the Donabedian theoretical framework to the study of PIVC insertion and management practices in paediatric patients was conducted. The chosen framework should provide a comprehensive insight of PIVC insertion and care in paediatric patients and to guide the study constructs, methodology and methods to achieve the overarching study goals. Among the five frameworks discussed above, the Donabedian framework is considered as the most potential framework to be used in the study to assess paediatric peripheral intravenous catheter insertion and care service from the point of views of healthcare providers, healthcare staff and also patients and families.

\section{DISCUSSION}

The three domains of structure, process and outcome in the Donabedian framework allows researchers or stakeholders to obtain more comprehensive picture of care delivery. These three elements are interdependent with each directly influenced by the antecedent [17]. By stressing the linkage between the three parts, the Donabedian model emphasizes that health care outcomes cannot be understood in isolation, but only by first examining the effectiveness of the structure and the processes of care that produce those outcomes [26]. The improvements in the structure of care should lead to improvements in clinical processes, which should in turn improve patient outcome [18].

In summary, the Donabedian framework allows stakeholders particularly the healthcare team and researchers to assess not only the overall picture of care delivered but also to gain specific insights of each individual aspects of 
care such as the structures, processes and outcomes of the service [18, 19]. Therefore, the Donabedian framework is considered as the appropriate framework to assess the current overall picture of PIVC service delivery as well as investigates each part of the service from the structure, process and outcomes.

Nevertheless, the Donabedian framework provides only a generic guidance of essential domains of care that need to be assessed to obtain the current status of healthcare service delivered. To understand the prescriptive aspects of the specific care being examined in a study and its interrelationships, examination of research in this specific area should be undertaken [27]. The use of Donabedian framework needs further explanation if implemented in a specific area of care. In the nursing domain, Jones (2016) extrapolated sensitive examples of the Donabedian StructureProcess-Outcome model from several nursing care quality indicators publications [28-31]. The nurse sensitive examples of the structure of care includes nurse characteristics, care model, organisation accreditation and certification. The process of care comprises nurse surveillance, education and counselling, discharge planning, coordination of care, assistance with ambulation, medication administration and monitoring. The nurse sensitive example for outcomes such as patient self-care, health promoting behaviours, functional status, complications and adverse event, symptoms management, knowledge of disease and treatment, satisfaction with care, and health related quality of life [27].

Several published quality improvement studies in vascular access conducted in both the adult [21-24, 32] and paediatric population $[25,33]$ have utilised the Donabedian framework as an underpinning concept for their study. According to these studies, the structure indicators include amenities of venous access care [21], nurses' education, training and experience [23], hospital attributes (number of beds and annually patients visits, certification) and resources (number of skilled vascular access nurses, vascular access equipment, policy/guideline) [22, 25], patient profiles, and device characteristics [24]. The process indicators such as patient-practitioner interactions [21], vascular access insertion and maintenance care (frequency of dressing, maintenance of catheter patency, and attention to signs of inflammation) $[21,23,24]$. The outcomes include patient satisfaction and experience [21], first-attempt success, equipment used [22], pain [21] and catheter complication rates reduction [21-25].

A further criticism of the Donabedian framework is related to whom the structure-process-outcomes quality should be asked and whether this should be the patients, providers, policy makers, or all of these. [34]. Previous studies suggest that assessment of quality in healthcare relies heavily on the provider's perspective[35]. More recent studies indicate that providers may have different insights from the service users about the quality of the service and factors that important for the improvement of the service outcomes [20, 34-36]. Therefore, inclusion of patients' perspectives is needed to balance opinions [37]. Research recommends that data should be collected from providers as well as patients, andanalysed on a comparative basis to ensure that elements of services that patients view as important dimensions of quality are included in an appropriately weighted way [34].

\section{CONCLUSION}

Continuous assessment of healthcare service is essential to improve the quality of care provided. In order to assess the current status of healthcare service, health professionals and researchers in particular need to be aware of the structureprocess and outcome indicators specific to the service. The Donabedian S-P-O framework allows researchers to comprehensively understand the current status of healthcare services or practices being evaluated, not only from the outcome perspective but also from the antecedent factors (structure and process) and construct the quality improvement project based on the evaluation of the structure, process and outcomes of the current service [28]. The structure gives the quality perspective from the providers, the process provides insights from both provider and patients activities in the care, and the outcome provides the objectives as well as subjective measures of the care results [25]. Therefore, the Donabedian framework can be used as a potential model to guide the assessment of healthcare service in general and current paediatric peripheral intravenous catheter insertion and care in particular, providing a structure of data collection and analysis.

\section{ACKNOWLEDGMENT}

This research has been undertaken as part of Ms Ferika Indarwati's $\mathrm{PhD}$ program. The researcher acknowledges the Indonesian Endowment Fund (LPDP), the Indonesian Ministry of Finance that provides scholarship funding for her PhD study.

\section{REFERENCES}

[1] exandrou E, Ray-Barruel G, Carr PJ, Frost S, Inwood S, Higgins N, et al. Use of short peripheral intravenous catheters: Characteristics, management, and outcomes worldwide. J Hosp Med. 2018;13(5).

[2] 2. Ben Abdelaziz R, Hafsi H, Hajji H, Boudabous H, Ben Chehida A, Mrabet A, et al. Full title: Peripheral venous catheter complications in children: Predisposing factors in a multicenter prospective cohort study. BMC Pediatr. 2017;17(1).

[3] 3. Birhane E, Kidanu K, Kassa M, Gerezgiher D, Tsegay L, Weldu $\mathrm{B}$, et al. Lifespan and associated factors of peripheral intravenous Cannula among infants admitted in public hospitals of Mekelle City, Tigray, Ethiopia, 2016. BMC Nurs. 2017;16(1):33.

[4] 4. Malyon L, Ullman AJ, Phillips N, Young J, Kleidon T, Murfield $\mathrm{J}$, et al. Peripheral intravenous catheter duration and failure in paediatric acute care: A prospective cohort study. Emergency medicine Australasia : EMA. 2014;26(6):602-8.

[5] Hsieh Y, Huang L, Wang C: A framework for the selection of six sigma projects in services: case studies of banking and health care services in Taiwan. Serv Bus 2012, 6.

[6] Lee D: HEALTHQUAL: a multi-item scale for assessing healthcare service quality. Serv Bus 2016

[7] Raposo M, Alves H, Duarte P: Dimensions of service quality and satisfaction in healthcare: a patient's satisfaction index. Serv Bus 2009, 3.

[8] Scobie S, Thomson R, Mcneil J, Phillips P: Measurement of the safety and quality of healthcare. The Medical journal of Australia 2006, 184.

[9] Ant NM: The importance of Assessment Indicators Concerning Therapeutic Interventions, Operation of Health Services and Population's Health in the Matter of Health Policy Planning. The Scientific Journal of the Hellenic Regulatory Body of Nurses 2009, 2(1):8-13.

[10] Montagu D: Accreditation and other external quality assessment systems for healthcare. In. California: DFID Health Systems Resource Centre 2003.

[11] Spath P: Introduction to healthcare quality management, 2nd edn: Health Administration Press Chicago; 2014. 
[12] Clarke A: Evaluation research in nursing and health care. Nurse Researcher (through 2013) 2001, 8(3):4.

[13] Donabedian A: An introduction to quality assurance in health care. New York: Oxford University Press; 2003.

[14] Polit DF, Beck CT: Nursing research: Generating and assessing evidence for nursing practice, 10th edn. Philadelphia: Wolters Kluwer Health; 2017.

[15] Ovretveit J: Health service quality: an introduction to quality methods for health services: Blackwell Scientific; 1992.

[16] Zabada C, Rivers PA, Munchus G: Obstacles to the application of total quality management in health-care organizations. Total quality management 1998, 9(1):57-66.

[17] Douglas TJ, Fredendall LD: Evaluating the deming management model of total quality in services. Decision Sciences 2004, 35(3):393422.

[18] Larrabee JH: Emerging model of quality. IMAGE: the Journal of Nursing Scholarship 1996, 28(4):353-358.

[19] Parasuraman A, Zeithaml VA, Berry LL: A conceptual model of service quality and its implications for future research. Journal of marketing 1985, 49(4):41-50.

[20] Parasuraman A, Zeithaml V, Berry L: SERVQUAL: a multiple item scale for measuring consumer perceptions of service quality. J Retail 1988, 64.

[21] Donabedian A: The methods and findings of quality assessment and monitoring: An illustrated analysis. J healthc qual 1985, 7(3):15.

[22] Gardner G, Gardner A, O'Connell J: Using the Donabedian framework to examine the quality and safety of nursing service innovation. Journal of clinical nursing 2014, 23(1-2):145-155.

[23] Naranjo LLS, Kaimal PV: Applying donabedian's theory as a framework for bariatric surgery accreditation. Bariatric Nursing and Surgical Patient Care 2011, 6(1):33-37.

[24] Kobayashi H, Takemura Y, Kanda K: Patient perception of nursing service quality; an applied model of Donabedian's structure - process - outcome approach theory. Scandinavian journal of caring sciences 2011, 25(3):419-425.

[25] Beerman ALMSNA-BC: Making the case for a nurse-led vascular access team utilizing a quality assurance conceptual framework. Journal of the Association for Vascular Access 2009, 14(2):77-82.

[26] Campos CL: Improving patient outcomes in nurse-placed vascular access devices. Capella University; 2019.

[27] Kadium MJ: Improving nurses' knowledge to reduce catheter-related bloodstream infection in hemodialysis unit. Walden University; 2015.
[28] de Souza Menezes VP, Bittencourt AR, de Menezes MdFB: Infection related to central venous catheter: Indicator of quality of care in oncology. Revista de Pesquisa: Cuidado é Fundamental Online 2013, 5(3):373-385.

[29] Reid J: Nursing care for pediatric patients with central venous access devices. 2015.

[30] Donabedian A: The quality of care: how can it be assessed? Jama 1988, 260(12):1743-1748.

[31] Jones T: Outcome measurement in nursing: Imperatives, ideals, history, and challenges. OJIN: The Online Journal of Issues in Nursing 2016, 21(2).

[32] Doran DM, Pringle D: Patient outcomes as accountability. In: Nursing outcomes: The state of the science. 2nd edn. Edited by Doran D. Sudbury, MA: Jones \& Bartlett Learning; 2011: 1-27.

[33] Burston S, Chaboyer W, Gillespie B: Nurse - sensitive indicators suitable to reflect nursing care quality: a review and discussion of issues. Journal of clinical nursing 2014, 23(13-14):1785-1795.

[34] Dubois C-A, D'Amour D, Pomey M-P, Girard F, Brault I: Conceptualizing performance of nursing care as a prerequisite for better measurement: a systematic and interpretive review. BMC nursing 2013, 12(1):7.

[35] Heslop L, Lu S: Nursing - sensitive indicators: a concept analysis. Journal of advanced nursing 2014, 70(11):2469-2482.

[36] Verhoeff K, Saybel R, Mathura P, Tsang B, Fawcett V, Widder S: Ensuring adequate vascular access in patients with major trauma: a quality improvement initiative. BMJ Open Qual 2018, 7(1):e000090.

[37] Hartman JH, Baker J, Bena JF, Morrison SL, Albert NM: Pediatric vascular access peripheral iv algorithm success rate. Journal of Pediatric Nursing 2018, 39:1-6.

[38] Peabody JW, Taguiwalo MM, Robalino DA, Frenk J: Improving the quality of care in developing countries. In: Disease Control Priorities in Developing Countries (2 ed). edn. Edited by D. Jamison JB, A. Measham, G. Alleyne, M. Claeson, D. Evans, P. Jha, A. Mills, \& P. Musgrove. Washington DC: World Bank Group; 2006.

[39] Schembri S: Experiencing health care service quality: through patients' eyes. Australian Health Review 2015, 39(1):109-116.

[40] McGlynn EA: Six challenges in measuring the quality of health care. Health affairs 1997, 16(3):7-21.

[41] Cooke M, Ullman AJ, Ray-Barruel G, Wallis M, Corley A, Rickard CM: Not "just" an intravenous line: Consumer perspectives on peripheral intravenous cannulation (PIVC). An international crosssectional survey of 25 countries. Plos One 2018, 13(2):e0193436e0193436. 